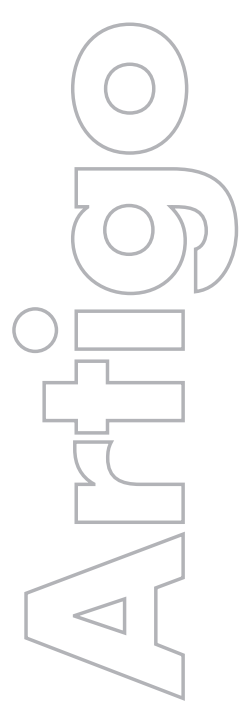

revista

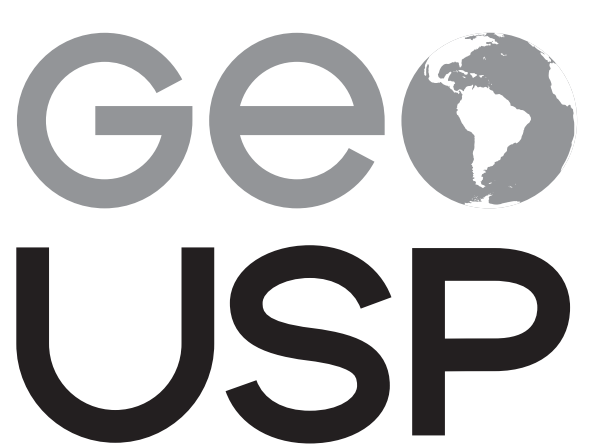

espaço e tempo

Volume $23 \cdot n^{\circ} 1$ (2019)

ISSN 2179-0892
Da banalização das regiões metropolitanas ao Estatuto da Metrópole: será o fim das "metrópoles de papel"?

\section{Eduardo Celestino Cordeiro}

UFRJ

e-mail: celestinocordeiro@yahoo.com.br

p. $040-058$

Como citar este artigo:

CORDEIRO, E. C. Da banalização das regiões metropolitanas ao Estatuto da Metrópole: será o fim das "metrópoles de papel"? Geousp - Espaço e Tempo (Online), v. 23, n. 1, p. 040-058, abr. 2019. ISSN 2179-0892.

Disponível em: https://www.revistas.usp.br/geousp/article/ view/141746. doi: https://doi.org/10.11606/issn.2179-0892. geousp.2019.141746.

\section{(c) $(1) \circledast$}

Este artigo está licenciado sob a Creative Commons Attribution 4.0 License. 


\title{
Da banalização das regiões metropolitanas ao Estatuto da Metrópole: será o fim das "metrópoles de papel"?
}

\section{Resumo}

Ortigo analisa implicações da lei federal denominada Estatuto da Metrópole na banalização da criação de regiões metropolitanas (RM) no Brasil. Estudou-se o caso do Maranhão, a partir da perspectiva que entende essas regiões como meios institucionais pelo quais agentes políticos territorializam o espaço para viabilizar seus objetivos. Constatou-se que a lei federal refreou as tentativas de se criarem novas RM no Maranhão, mas não impediu a manutenção e a inclusão de município para além da conurbação intermunicipal das "metrópoles" das regiões já existentes; o que pode vir a ocorrer também nos outros estados, significando não o fim das "metrópoles de papel", mas o crescimento territorial das já existentes.

Palavras-chave: Regiões metropolitanas. Estatuto da Metrópole. Instituição metropolitana. Metrópoles de papel.

\section{The banalization of the Metropolitan Regions to Statute of the Metropolis: will it be the end of "paper metropolis"?}

\begin{abstract}
The paper analyzes the implications of federal law called the Statute of the Metropolis on the routine creation of Metropolitan Regions (MRs) in Brazil. The case of Maranhão was studied, from the perspective that understands these regions as institutional means by which political agents territorialize the space to make feasible its objectives. In conclusion, it was verified that the federal law stopped the attempts to create new RMs in Maranhão, but did not prevent the maintenance and inclusion of towns for beyond the conurbation of the "metropolises" of the existing regions; which may also occur in the other states, meaning not the end of the "paper metropolis", but the territorial growth of the already existing ones.
\end{abstract}

Keywords: Metropolitan Regions. Statute of the Metropolis. Metropolitan institution. Metropolis of paper. 


\section{Introdução}

Na década de 1970, a União criou nove regiões metropolitanas (RM) no Brasil, prerrogativa que então lhe era reservada. A partir de 1988, entretanto, quando os estados passaram a ter competência exclusiva para instituir as próprias RM, o número aumentou sensivelmente em menos de três décadas, mas a maioria dessas regiões administrativas não abarca espaços metropolitanos, deflagrando uma banalização do instrumento territorial. Objeções a isso não faltaram, e, em 2015, a lei federal denominada Estatuto da Metrópole (EM) (Brasil, 2015) surge como uma promessa para pôr limites a tal fenômeno.

Esse quadro talvez resuma bem o contexto da questão em tela, mas é preciso fazer alguns adendos. Primeiro, a emergência das RM brasileiras como formas territoriais para a ação governamental é marcada pelo autoritarismo e pela centralização da parte de uma esfera de governo sobre outras (Souza, 2003, 2004). Em segundo lugar, depois da Constituição Federal (CF) de 1988 (Brasil, 1988), apesar da margem legal para tanto, o salto numérico de RM criadas pelos estados não foi imediato. Por último, quando proposto o EM, em 2004, já era evidente a banalização do referido instrumento.

Alguns pontos guardam estreita relação. A associação histórica da RM aos objetivos de centralização e controle do regime militar (1967-1985) contrastava com os anseios políticos da Constituinte de 1988, que deu à matéria um tratamento periférico (Souza, 2004). Nada distante das constituições estaduais elaboradas no ano seguinte que, em sua maioria, não estabeleceram definições de RM pautadas em critérios funcionais de identificação dos espaços metropolitanos (Azevedo; Guia, 2004). Daí decorre que a hesitação inicial de muitos estados em criarem suas RM estivesse mais ligada ao estigma do período autoritário do que a restrições legais.

Mas certo sinal de ruptura ocorreu no início deste século, quando uma profusão de novas RM emerge pelo Brasil. Se, em tese, a instituição de RM é uma resposta política a questões associadas ao espaço metropolitano, o aumento do número desses territórios denotaria o crescimento de localidades onde municípios distintos se veem em conurbação com uma metrópole. Porém, como se verá adiante, não é esse o caso, pois a maioria dessas regiões são espaços sem configuração metropolitana; suas cidades-sede não passam de "metrópoles de papel", como afirmou Cunha (2005) no caso de Londrina.

De qualquer modo, em meio às tentativas de se criarem RM no Brasil, o EM surge como proposta de um novo marco legal para tais iniciativas. Entre outros pontos, ele traria definições que diferenciassem as RM das outras formas territoriais previstas no Artigo 25 da CF, isto é, as aglomerações urbanas $(\mathrm{AU})$ e as microrregiões. Exigiria ainda a observação de critérios para seleção dos espaços instituídos como metropolitanos, de modo a evitar a banalização do instrumento. Hoje em vigor, o EM realmente trouxe diretrizes nesses dois sentidos, mas resta saber se alcançará os efeitos pretendidos.

Nesse contexto, o presente trabalho visa analisar as implicações do EM na banalização das RM no Brasil, para responder se realmente a lei tem a capacidade de inibir esse fenômeno. A análise se baseia no caso do Maranhão e permite identificar: (1) onde estão formalmente 
enquadradas as atuais RM aí instituídas: (2) as possibilidades de se criarem novas conforme as definições do EM e as condições espaciais encontradas no estado e (3) a repercussão da lei federal em deliberações legislativas atinentes às RM maranhenses.

Para a exposição dos resultados, a próxima seção descreve os fundamentos legais e a incidência espacial do fenômeno aqui denominado banalização das regiões metropolitanas no Brasil. Em seguida, analisa-se o EM de modo a identificar, em suas definições e critérios, o que a lei caracteriza como RM ou AU, diretrizes a ser observadas pelos estados ao instituírem tais regiões. Na última seção antes da conclusão, o contexto das instituições de RM no Maranhão é apresentado junto com o exercício de enquadramento regional conforme as definições e critérios estabelecidos pelo EM.

\section{A banalização da criação de regiões metropolitanas no Brasil: manifesta- ção do fenômeno e sua viabilidade legal}

A manifestação do fenômeno: quando e onde surgem as "metrópoles de papel"?

Há uma interpretação corrente segundo a qual, ao criar as primeiras RM no Brasil, o governo federal não primou por contemplar apenas os espaços metropolitanos. Fosse por "necessidades da estratégia de desenvolvimento econômico assumido" (Araújo Filho, 1996, p. 57) ou para servir como "braços avançados do governo federal nos territórios mais dinâmicos da federação" (Souza, 2004), a seleção dos territórios assim instituídos na década de 1970 não estaria limitada aos municípios conurbados a metrópoles.

Mas, rigorosamente, essa não era condição necessária para que dado conjunto de municípios fosse instituído como metropolitano. Isso porque a CF de 1967 não restringia a aplicação de tal instituto as áreas abarcadas por metrópoles; referia-se apenas a municípios que integrassem "a mesma comunidade sócio-econômica, visando à realização de serviços de interesse comum" (Art. 157, § 10).

E mais, a União teria certo aval técnico, pois, segundo Araújo Filho (1996), a seleção das nove RM instituídas na época teria sido baseada em estudos colaborativos entre o Ministério do Planejamento (por meio do Escritório de Pesquisa Econômica Aplicada [Epea], atual Instituto de Pesquisa Econômica Aplicada [Ipea]) e o Instituto Brasileiro de Geografia e Estatística (IBGE).

Polêmicas à parte, a tese de que a instituição de RM no Brasil ultrapassa os espaços efetivamente metropolitanos se confirma (e salta aos olhos) no contexto pós-1988.

Com a CF de 1988, são novos os condicionantes legais relativos à instituição de RM. Agora a cargo dos estados, a criação desses territórios atingiu até o fim de 2018 o total de 76 unidades - além de três regiões integradas de desenvolvimento econômico (Ride)' e quatro aglomerações urbanas (AU). A cronologia do processo revela o acentuado crescimento de RM instituídas depois de 1988, como se vê no Gráfico 1.

1 As Ride seguem pressupostos e propósitos similares aos das RM, mas abrangem mais de um estado e foram instituídas pelo governo federal com base nos artigos 21, 43 e 48 da CF. São as seguintes: a do Distrito Federal e Entorno (GO e MG), a da Grande Teresina (PI e MA) e a de Petrolina-Juazeiro (PE e BA). 


\section{Gráfico 1 - Crescimento do número de regiões metropolitanas no Brasil}

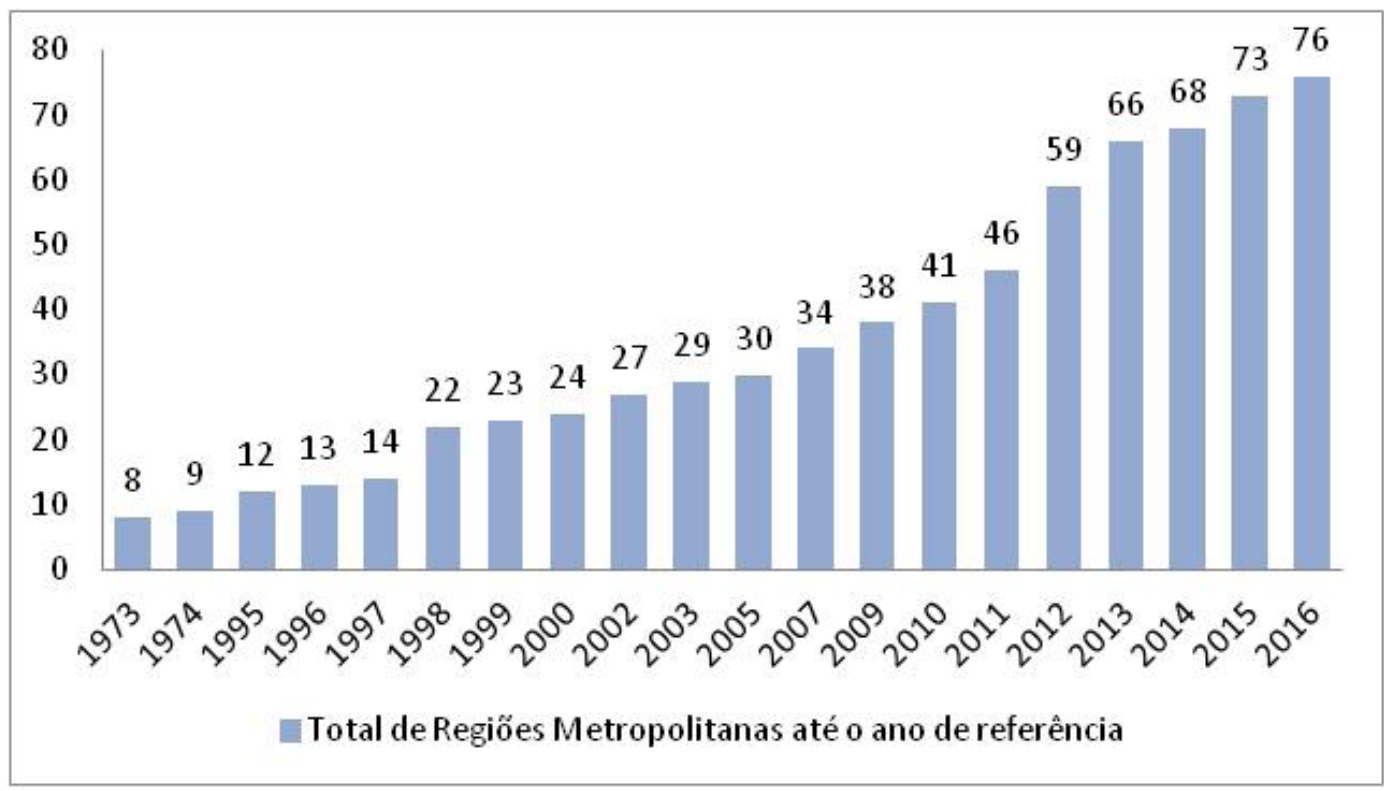

fonte: Elaborado a partir das leis de criação das respectivas RM.

No Gráfico 1, são identificados quatros períodos nos quais a criação de RM se deu em ritmos distintos. $\bigcirc$ primeiro corresponde às nove instituídas pela União nos anos de 1973 e 1974. Depois, da promulgação da CF, em 1988, até 2002, criaram-se mais 18 RM, excetuando-se as refundações legais. No terceiro intervalo, em cujo primeiro ano se cria o Ministério das Cidades, em 2003, formalizam-se mais 11 regiões em seis anos. Já o maior ritmo é registrado no quarto período, pois, em seis anos (entre 2010 e 2016), foram criadas 38 RM - simultaneamente aos trabalhos da Comissão Especial do EM (2011-2014) e de sua promulgação em forma de lei.

\section{Gráfico 1 - Crescimento de regiões metropolitanas no Brasil por período}

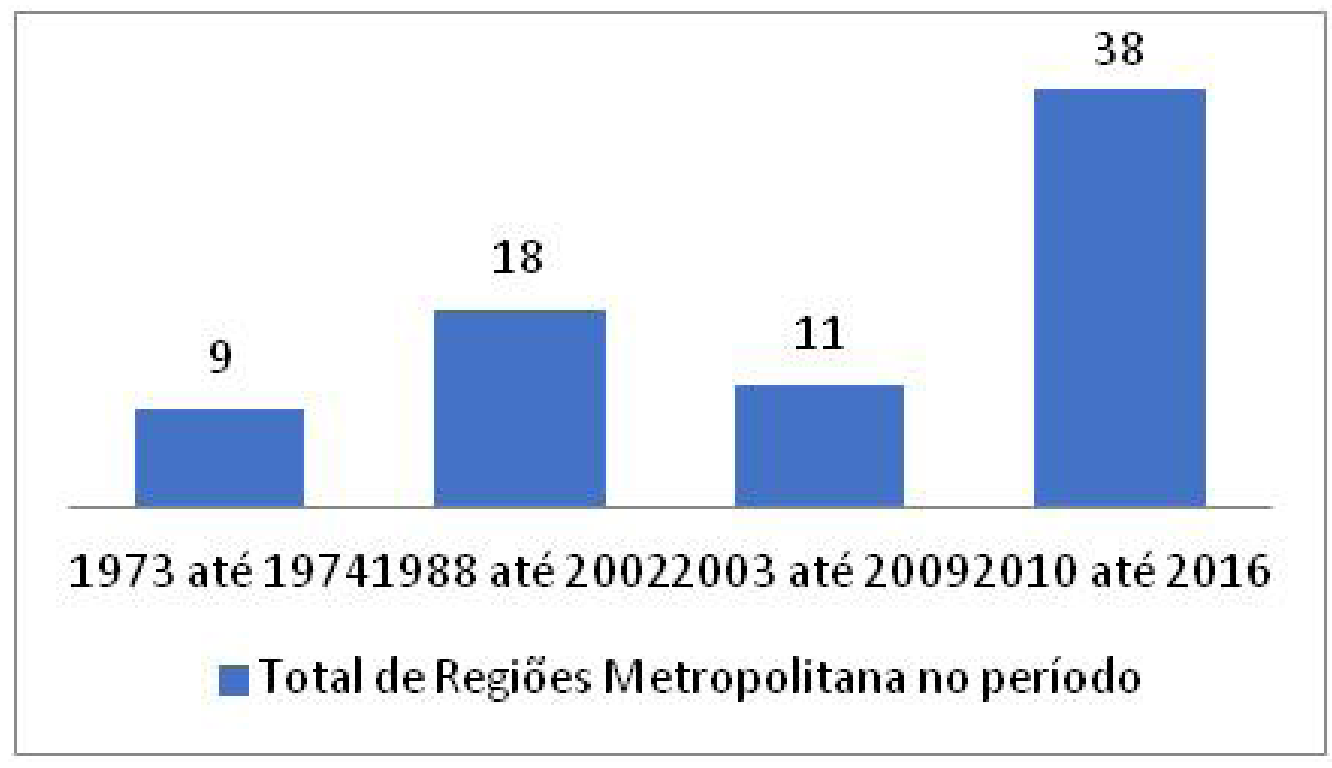


Vendo apenas pelo prisma da lei, estaríamos, então, diante de uma realidade nacional marcada por espaços metropolitanos. Nessa perspectiva, quase todos os estados brasileiros apresentariam pelo menos uma metrópole ou região em processo de metropolização (Mapa 1), com exceção do Mato Grosso do Sul e do Acre.

\section{Mapa 1 - Regiões metropolitanas e Ride no Brasil até 2018}

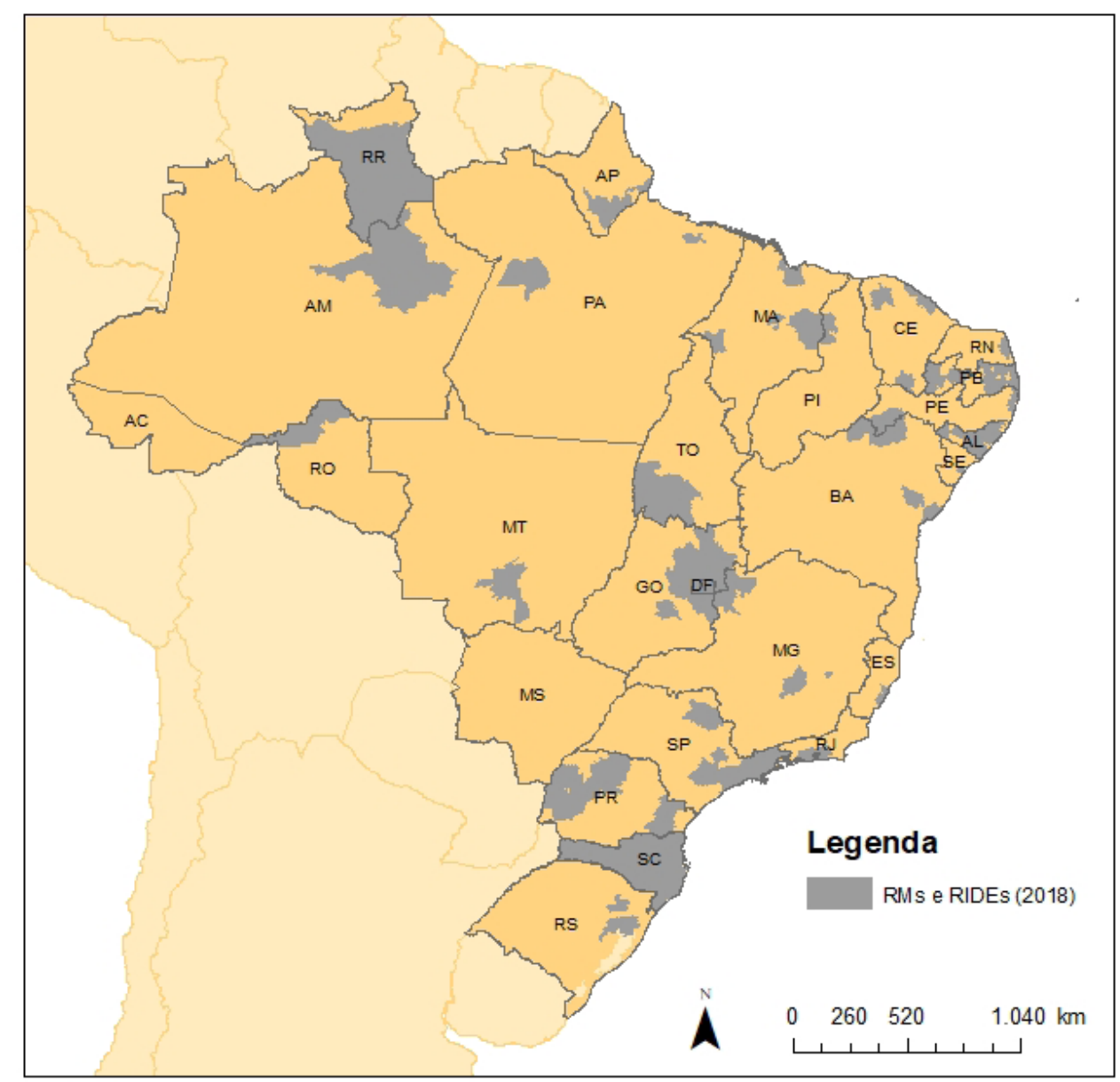

fonte: Elaborado pelo autor.

No entanto, o rápido aumento do número de RM formais não corresponde à realidade espacial desse fenômeno metropolitano no país. Isso quando consideradas análises da urbanização do espaço brasileiro como as da série regiões de influência das cidades (Regic), produzidas pelo IBGE nos anos de 1987, 1993 e 2007. Segundo a última Regic (IBGE, 2008), até 2007, existiam no país 12 metrópoles, ${ }^{2}$ cidades que são também sede de alguma RM ou, no caso de Brasilia, Ride (Mapa 2).

Todavia, isso não significa que, além das metrópoles identificadas pelo IBGE, em outras cidades brasileiras os processos urbanos não se estivessem (nem estejam) formando espaços metropolitanos. Inclusive, em 2015, o órgão federal identificou 26 espaços cuja dinâmica e

2 O nome e o respectivo tipo urbano são São Paulo, a grande metrópole nacional, Rio de Janeiro e Brasilia, metrópoles nacionais, e Manaus, Belém, Fortaleza, Recife, Salvador, Belo Horizonte, Curitiba, Goiânia e Porto Alegre, demais metrópoles brasileiras. 
configuração evidenciam processos e formas típicos da metropolização (IBGE, 2015). Apesar de a maioria não reunir condições suficientes que caracterizam uma metrópole, todos esses espaços apresentam indicadores próximos aos lineares metropolitanos considerados pelo IBGE no estudo citado de 2008.

Trata-se dos arranjos populacionais de grande concentração urbana (GCU), um tipo de arranjo populacional (AP) de maior porte. Esses são recortes espaciais nos quais municípios foram agrupados segundo critérios de integração "medida pelos movimentos pendulares para trabalho e estudo ou a contiguidade urbana" (IBGE, 2015).

Já o conceito de GCU refere-se aos AP "acima de 750.000 habitantes e os municípios isolados (que não formam arranjos) de mesma faixa populacional", considerados também segundo "a magnitude de sua forma e dos seus aspectos econômicos" (IBGE, 2015, p. 49).

Vistas a partir da hierarquia dos centros urbanos (IBGE, 2008), as GCU revelam três situações. A mais óbvia é o fato de as 12 metrópoles brasileiras estarem situadas em GCU afinal, as condições distintivas destas estão implícitas nas dos centros metropolitanos. $\bigcirc$ mesmo acontece com as 11 cidades de nível imediatamente inferior ao das metrópoles, isto é, as capitais regionais A - a primeira das três classes do nível, diferenciadas pelas letras A, B e C. Por fim, das 39 capitais regionais C, três são abrangidas por GCU (Mapa 2).

\section{Mapa 1 - Distribuição das grandes concentrações urbanas - Brasil - 2010}

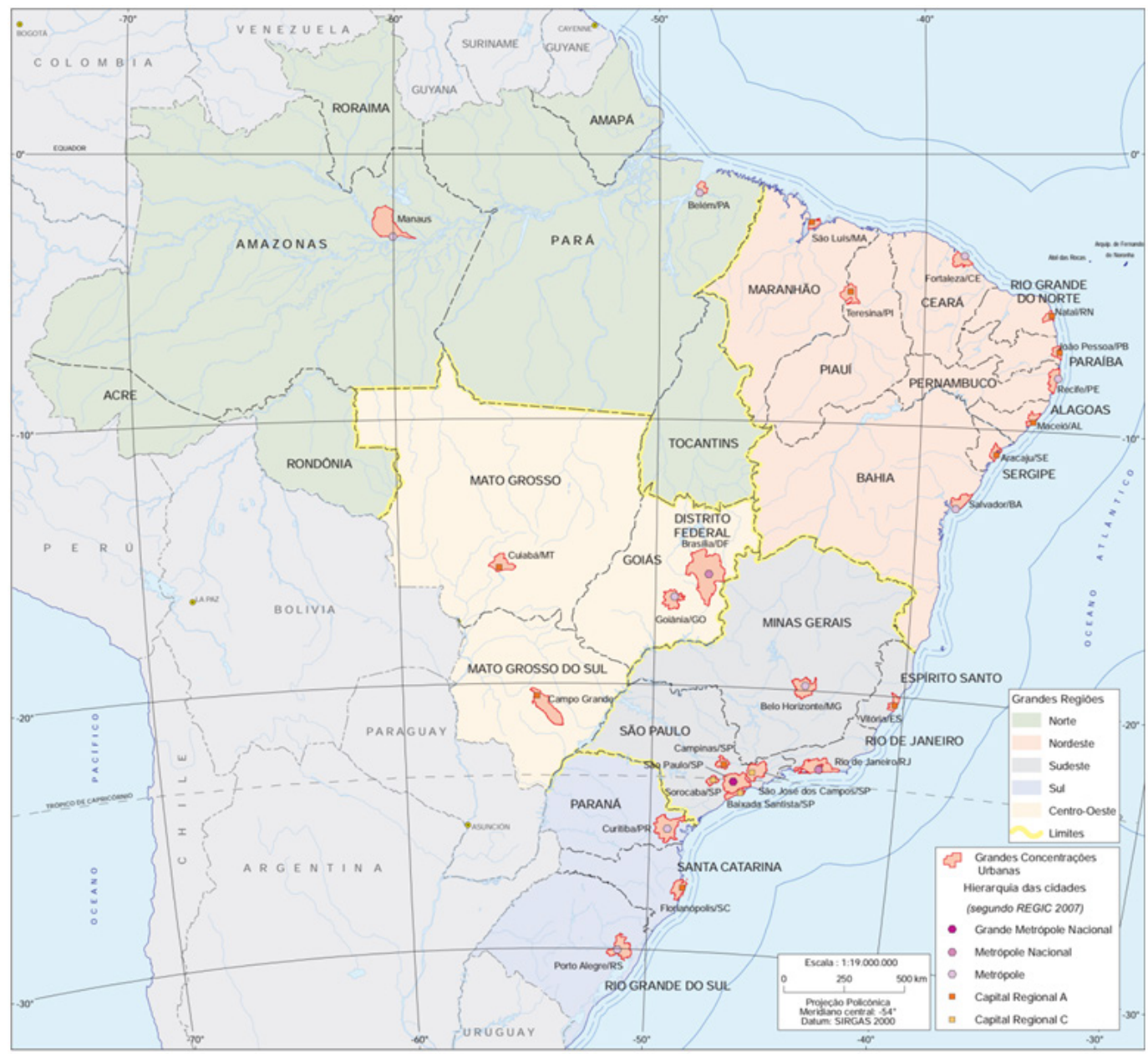

fonte: IBGE (2015, p. 50). 
Então, as GCU reúnem cidades situadas nos dois primeiros níveis da hierarquia dos centros urbanos. Em termos espaciais, isso significa forte integração intermunicipal (indicada pelo fluxo diário de pessoas e a mancha urbana por onde circulam) e ampla área de influência (medida a partir da concentração de atividades-chave para os fluxos econômicos e políticos). Mesmo assim, nem todas correspondem a espaços metropolitanos.

Como se verá, as GCU se enquadram na definição de RM encontrada no EM, por abarcar metrópoles ou capitais regionais. Já o conceito de AP satisfaz a definição de AU presente na lei, pois diz respeito a um conjunto de municípios com forte complementaridade funcional e integração espacial. Os indicadores utilizados pelo IBGE aferem tanto os fluxos (no caso, o movimento pendular a trabalho ou estudo) como os fixos (das manchas urbanas intermunicipais) característicos do processo de conurbação.

Esse é um ponto relevante e será aqui demonstrado em momento oportuno. Antes, cabe ressaltar que, das $26 \mathrm{GCU}$, só a de Campo Grande, no Mato Grosso do Sul, não faz parte de RM ou Ride. Serão, pois, de instituições metropolitanas condizentes com a realidade empírica que pressupõem?

A resposta depende do espaço em questão e pode ser negativa quando considerados os limites da região - como no caso maranhense aqui estudado. Aliás, em escala nacional, nota-se que 47 RM instituídas no país nem mesmo abrangem áreas classificadas como GCU, como se depreende da comparação dos Mapas 1 e 2. Quaisquer que tenham sido as motivações políticas do fenômeno, ele tem sua viabilidade legal na própria CF, condicionantes identificadas no próximo tópico.

\section{A viabilidade legal das "metrópoles de papel": condicionantes constitu- cionais}

Em matéria de instituição de RM, a CF dá ampla liberdade aos estados. Trata-se de um direito subjetivo, competência a ser exercida de acordo com os princípios da conveniência e discricionariedade, seguindo o modal do permitido, não o obrigatório (Serrano, 2009). Essa liberdade legislativa é reconhecida na doutrina jurídica, que também constata haver indefinições constitucionais sobre a matéria, sendo isso razão de controvérsias políticas e jurídicas (Paula, 2013).

Na verdade, há alguns limites constitucionais que os legisladores estaduais devem obedecer ao criarem suas RM. A lei maior do Brasil, no parágrafo $3 \circ$ do Artigo 25, exige três condições para o exercício dessa competência: (a) que se dê por lei complementar, (b) que incida em agrupamentos de municípios limítrofes e (c) que tenha o objetivo de "integrar a organização, o planejamento e a execução de funções públicas de interesse comum". ${ }^{3}$

mesmo se exige das outras duas formas regionais previstas no dispositivo legal, as $\mathrm{AU}$ e as microrregiões. Assim, a CF apresenta uma categoria regional dividida em três classes, mas, além do enunciado nominal, nada mais diz sobre a diferenciação material de cada uma. E aí está a "abertura" constitucional que autoriza os estados a trabalharem com definições próprias de RM, AU e microrregião.

3 Na íntegra: "Os Estados poderão, mediante lei complementar, instituir regiões metropolitanas, aglomerações urbanas e microrregiões, constituídas por agrupamentos de municípios limítrofes, para integrar a organização, o planejamento e a execução de funções públicas de interesse comum" (Brasil, 1988, Art. 25, §3॰). 
Não obstante possibilitar aos legisladores criarem RM compatíveis com a realidade espacial do respectivo estado, a mencionada "abertura" originária deu margem a semelhante indefinição por parte das Constituintes estaduais de 1989. De acordo com Azevedo e Guia (2004), na maioria das Constituições Estaduais não houve a preocupação de condicionar a criação de RM a critérios pautados na espacialidade metropolitana, que se limitaram a reproduzir as mesmas exigências e generalidade que constam na CF.

Por mais passível de questionamentos, certa definição legal que se remeta a critérios condizentes com a diferenciação espacial dos espaços metropolitanos permitiria "uma prevalência da discussão técnica sobre a política, na medida em que a criação de uma região metropolitana não depende exclusivamente da vontade e do interesse de grupos ou de políticos" (Firkowski, 2011, p. 9). Sem isso, a instituição de dada RM pode prescindir da realidade material que a pressupõe, o espaço metropolitano, e atender a objetivos distintos do, como diz a CF, "interesse comum" aos entes federados assim colegiados.

Nesses termos legais, há lugar para controversas interpretativas que pesam negativamente nos rumos políticos das RM como instâncias intergovernamentais. É isso que tem ocorrido, haja vista as contestações desta natureza dirigida ao Supremo Tribunal Federal (Paula, 2013) e a fragilidade do quadro institucional das RM no país (Costa; Tsukumo, 2013). Foi diante de tudo isso que a proposição do EM ganhou força, trazendo a promessa de dirimir divergências jurídicas e alinhar esforços políticos.

\section{Estatuto da Metrópole: os limites (federais) para a criação de regiões me- tropolitanas}

O EM (Brasil, 2015) advém do Projeto Legislativo n. 3.460, submetido à Câmara dos Deputados em 2004. Até então, havia 28 RM no país, mas outras 44 surgiram durante o trâmite da proposta. $\bigcirc$ projeto prometia, entre outros objetivos, estabelecer novos critérios para a instituição de RM e AU, de modo a garantir congruência entre o fato jurídico e a realidade empírica objeto de cada instrumento. Com efeito, o diploma legal traz definições nesse sentido, por dotar de circunscrição formal as palavras-chave encontradas no §3o do Artigo 25 da CFe estabelecer responsabilidades e critérios a serem observados pelos entes federados envolvidos nesse processo.

Por ora, interessam as alíneas I, V e VII do Art. 20 do EM, pois trazem definições de $\mathrm{AU}$, metrópole e RM, respectivamente. Elas dão ênfase à realidade espacial, com destaque aos processos característicos de conurbação e metropolização. Apesar de não contemplar a diversidade de configurações espaciais da metropolização brasileira (Moura; Hoshino, 2015), tais definições pretendem que essas instituições regionais partam da constatação empírica do que as pressupõe, na contramão das "metrópoles de papel".

No caso da "metrópole" e de sua "região metropolitana", o EM exige a observância de critérios não estabelecidos por deliberação legislativa, já que vincula as definições dessas categorias a conceitos adotados pelo IBGE, notadamente no Regic. Entretanto, no que se refere à definição de metrópole, o estatuto não se limita ao conceito adotado pelo Regic-2007, pois abarcou também as capitais regionais, conforme segue: 
Art. $2 \circ[\ldots] \mathrm{V}$ - metrópole: espaço urbano com continuidade territorial que, em razão de sua população e relevância política e socioeconômica, tem influência nacional ou sobre uma região que configure, no mínimo, a área de influência de uma capital regional, conforme os critérios adotados pela Fundação Instituto Brasileiro de Geografia e Estatística - IBGE (Brasil, 2015).

Nessa acepção, além das 12 metrópoles do Regic-2007, as capitais regionais podem ser formalmente enquadradas como metropolitanas, quando constituem um "espaço urbano com continuidade territorial". Então, ao lado da centralidade metropolitana e a das capitais regionais, a "metrópole" da lei deve apresentar esse segundo atributo. Mas de que se trata? Seria o espaço da conurbação formada por uma metrópole ou capital regional?

Entendemos que sim, desde que não se confunda a conurbação com sua clássica expressão paisagística, o amálgama de manchas urbanas, e sim se referindo ao espaço composto por cidades funcionalmente integradas por fluxos diários, dada a complementaridade socioeconômica. Nesse sentido, pode ocorrer onde há descontinuidade da mancha urbana entre municípios, quando existir forte integração funcional entre eles - veja-se o caso da macrometrópole paulista (Lencioni, 2004).

Aliás, tal concepção de conurbação é compatível com os atribuídos espaciais que caracterizam a AU definida pelo EM; diz o Art. 2, § I, que a "unidade territorial urbana constituída pelo agrupamento de 2 (dois) ou mais Municípios limítrofes [é] caracterizada por complementaridade funcional e integração das dinâmicas geográficas, ambientais, políticas e socioeconômicas" (Brasil, 2015). Então, satisfeita essa condição, a continuidade exigida é a das áreas jurisdicional dos municípios, e não a das manchas urbanas, sem descartar o fato de elas serem um indicador valioso de integração intermunicipal.

Quanto à definição de RM, o EM estabelece clara distinção com a AU - algo apenas subentendido na CF. Rigorosamente, a lei concebe a RM como um tipo particular de AU; segundo o Art. 2॰, § VII, a que "configure uma metrópole" (Brasil, 2015). Considerando essa acepção de "metrópole" e a noção de conurbação adotada aqui, podemos traduzir assim a RM definida no EM: conjunto de municípios limítrofes onde um se destaca como metrópole ou capital regional segundo critérios do IBGE e que, dados a centralidade urbana e processos de conurbação, forma um espaço urbano contínuo.

Assim elaborado, o conceito torna-se operacional para a tarefa da próxima seção, por coadunar a visão legal com a leitura espacial. E, não é demais frisar, ele incorpora duas escolhas implícitas na definição de "metrópole" do EM, a saber: (1) alarga a categoria para abarcar cidades fora do nível máximo da hierarquia urbana dos centros, isto é, o nível metropolitano, mas com relevantes centralidades urbanas, e (2) restringe essa acepção legal aos "espaços urbanos com continuidade territorial" entre municípios limítrofes.

Então, aos olhos do governo federal, quando dado conjunto de municípios limítrofes conjuga tais condições, além de se enquadrar na definição de $\mathrm{AU}$, satisfaz os pré-requisitos para ser instituído como RM. Inclusive porque as condições ocorrem em espaços recortados por mais de dois territórios estaduais, o Art. 4o do EM criou as figuras das RM e das AU instituídas por deliberação das respectivas assembleias legislativas (Brasil, 2015). 
Em última análise, segundo o Art. $1^{\circ}$ do EM, esse enquadramento faz parte dos "critérios para o apoio da União a ações que envolvam governança interfederativa no campo do desenvolvimento urbano" (Brasil, 2015). No caso das RM anteriores à lei, deve ser observado se atendem aos critérios definidos para a categoria, do contrário a região será tida como AU (cf. Art. 15). ${ }^{4}$, ainda nos termos da lei, o que vale para RM e AU é extensível às Ride. ${ }^{5}$

\section{Institucionalização de regiões metropolitanas no Maranhão e o Estatuto da Metrópole}

Apesar de o instrumento legal para se criarem RM no Brasil ser a Lei Complementar, desde 1989, a Constituição do Estado do Maranhão, no Art. 19 do Ato das Disposições Constitucionais Transitórias, define como criada a RM da Grande São Luís (RMGSL). 6 Não sendo esse dispositivo objeto de ação direta de inconstitucionalidade, ele ainda consta na lei e data a criação da primeira RM instituída por iniciativa estadual no país. ${ }^{7}$ De todo modo, a efetiva regulamentação da RMGSL, isto é, a definição legal de sua abrangência, organização e funções, só ocorreu em 1998, via Lei Complementar Estadual (LCE) n. 38.

Inicialmente, a RMGSL era composta pelos municípios São José de Ribamar, Paço do Lumiar e Raposa, além da capital (Maranhão, 2003), mas outros nove foram incorporados ao longo de quatro alterações legislativas (Maranhão, 2013b, 2013a, 2015). Atualmente, a composição territorial da região é definida pela LC n. 174 (Maranhão, 2015), que abrange os seguintes municípios: Alcântara, Axixá, Bacabeira, Cachoeira Grande, Icatu, Morros, Presidente Juscelino, Paço do Lumiar, Raposa, Rosário, Santa Rita, São José de Ribamar e São Luís.

A Constituinte maranhense também previa a Região Metropolitana de Pedreiras (RMGP), na mesorregião Centro Maranhense. Apesar de removida pela emenda n. 042, de 2003, essa determinação foi cumprida por meio da LC n. 26, de 21 de fevereiro de 1995 , que define como integrantes da região os municípios de Pedreiras, Joselândia, Lima Campos, Trizidela do Vale, Bernardo do Mearim, Igarapé Grande, Lago dos Rodrigues e Poção de Pedras.

$\bigcirc$ estado também conta com a Região Metropolitana do Sudoeste Maranhense (RMSM), criada pela LCE n. 089, de 17 de novembro de 2005, e composta pelos municípios de Imperatriz, João Lisboa, Senador La Roque, Buritirana, Davinópolis, Governador Edison Lobão, Montes Altos e Ribamar Fiquene.

Por último, a Região Metropolitana do Leste do Estado do Maranhão (RMLEM) foi a quarta instituída no estado, por meio da LC n. 180, de 5 de janeiro de 2016. Sem alterações legislativas, a abrangência da região inclui os municípios de Parnarama, Matões, Caxias, São

4 "Art. 15. A região metropolitana instituída mediante lei complementar estadual que não atenda ao disposto no $\S$ VII do caput do art. 20 desta Lei será enquadrada como aglomeração urbana para efeito das políticas públicas a cargo do Governo Federal, independentemente de as ações nesse sentido envolverem ou não transferência de recursos financeiros".

5 "Art. 22. As disposições desta Lei aplicam-se, no que couber, às regiões integradas de desenvolvimento que tenham características de região metropolitana ou de aglomeração urbana, criadas mediante lei complementar federal, com base no art. 43 da Constituição Federal, até a data de entrada em vigor desta Lei".

6 "Art. 19. Fica criada a Região Metropolitana da Grande São Luís, com a abrangência, organização e funções definidas em lei complementar" (Maranhão, 1989a, p. 108).

7 "Parágrafo único. Lei Complementar criará Regiões Metropolitanas, nos termos do disposto neste artigo." (Maranhão, 1989a, p. 108). 
João do Sóter, Aldeias Altas, Codó e Timon. Aliás, este município também faz parte da Região Integrada de Desenvolvimento da Grande Teresina (RIDEGT), instituída pela União pelo Decreto n. 4.367, de 9 de setembro de 2002, que regulamentou a Lei Federal n. 112, de 19 de setembro de 2001. Além de Timon, a Ride é composta pelos municípios piauienses de Altos, Beneditinos, Coivaras, Curralinhos, Demerval Lobão, José de Freitas, Lagoa Alegre, Lagoa do Piauí, Miguel Leão, Monsenhor Gil e Teresina. A localização dessa e das demais regiões arroladas está no Mapa 3.

\section{Mapa 3 - Mapa com RM e Ride localizadas em território maranhense}

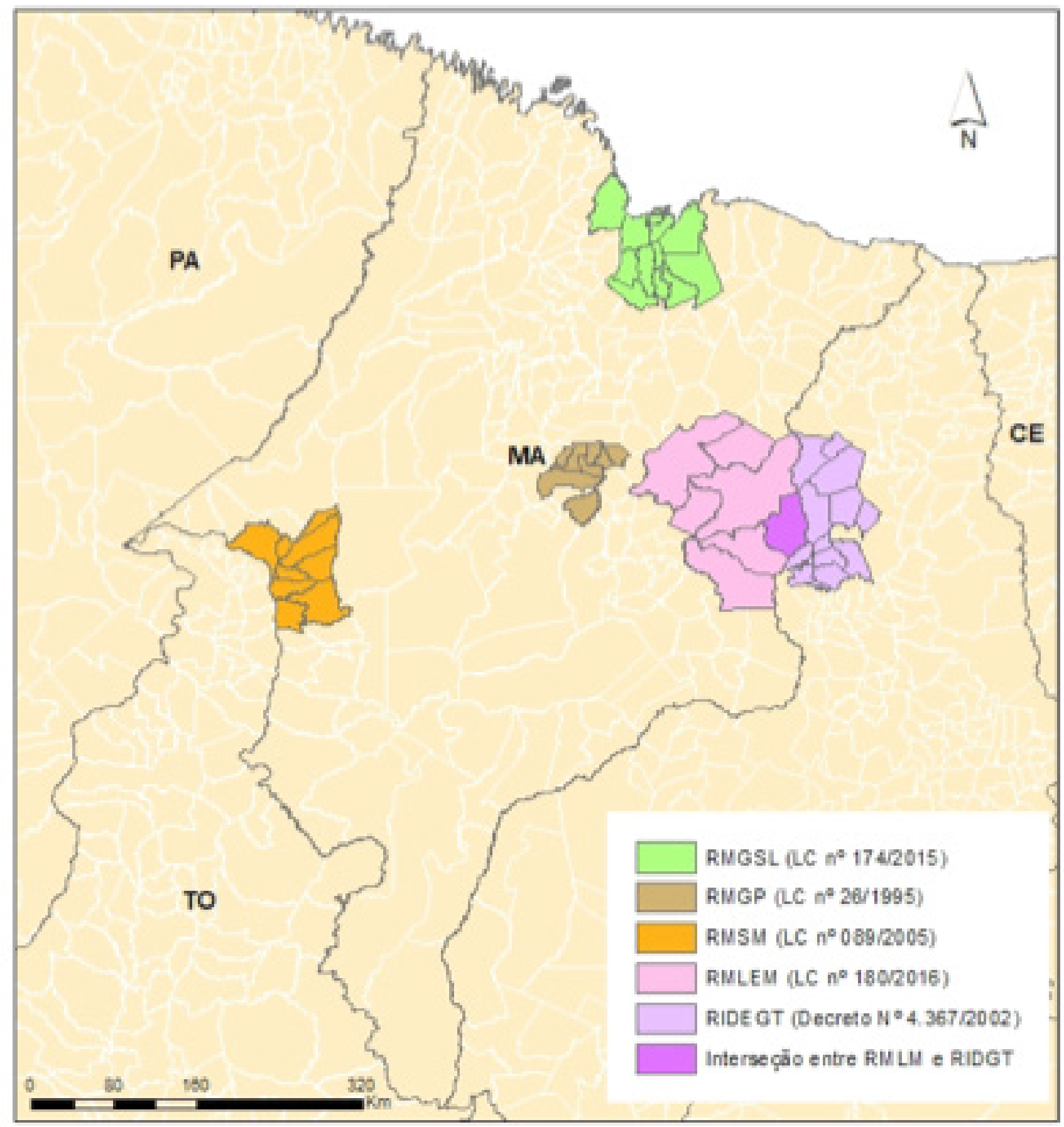


Ademais, importa considerar que, entre as regiões listadas acima e criadas antes do EM, só a da Grande São Luís recebeu reformulação legislativa. $\bigcirc$ novo diploma legal da região, inclusive, cita expressamente o $\mathrm{EM}$, para se referir a instrumentos aí previstos e indicar a possibilidade de aplicação subsidiária da lei federal no que couber. No entanto, manteve os municípios até então anexados à região e acrescentou outros, sem observar explicitamente os critérios do diploma federal citado. Quanto à RMGLEM, apesar de ser instituída depois da citada lei federal, não traz nenhuma referência ao EM

\section{Enquadramento regional do espaço maranhense segundo definições e cri- térios do Estatuto da Metrópole}

Conforme exposto, as definições legais de RM e AU estão vinculadas a tipos específicos de configuração espacial segundo critérios adotados nas pesquisas Regic-2007 (IBGE, 2008) e arranjos populacionais e concentrações urbanas do Brasil (IBGE, 2015). Portanto, os resultados abaixo sintetizam as informações desses estudos no Maranhão, tendo como referência as definições e os critérios da Lei Federal n. 13.089/2015.

Segundo o Regic-2007, o Maranhão conta com duas capitais regionais: a de São Luís, enquadrada na classe A; e a de Imperatriz, na classe C. Assim, elas atendem a um dos critérios mínimos que o EM estabelece para caracterizar uma "metrópole". Nesse caso, o critério diz respeito a níveis de centralidade na hierarquia dos centros urbanos, mais precisamente o nível das metrópoles e o das cidades regionais. $\bigcirc$ mesmo ocorre com a Ride onde está Timon, município que, com mais três do Piauí (Demerval Lobão, Lagoa do Piauí e Teresina), compõe um AP (IBGE, 2015, p. 96) cujo núcleo é a capital regional A de Teresina (IBGE, 2008). Ao todo, a população do arranjo era de 986.831 pessoas, e ele foi classificado como GCU (IBGE, 2015, p. 119).

Em relação à RMLEM, apesar de Timon manter forte integração com uma capital regional A (Teresina), os demais municípios não formavam nenhum AP ou cidade classificada (pelo REGIC-2007) no nível imediatamente inferior à categoria metrópole. Já no caso da RMGP, os municípios Trizidela do Vale e de Pedreiras compunham, juntos, um AP (IBGE, 2015, p. 88), porém sem cidade do tipo capital regional. Resta saber se a constituição das regiões administrativas consideradas corresponde ao critério de "continuidade territorial" dos respectivos espaços urbanos, aquele relativo à conurbação da "metrópole" - que, no caso, são as capitais regionais. Como já defendido, para mensurar essa conurbação, o conceito de AP é útil, pois remete a um "agrupamento de dois ou mais municípios onde há uma forte integração populacional devido aos movimentos pendulares para trabatho ou estudo, ou devido à contiguidade entre as manchas urbanizadas principais" (IBGE, 2015, p. 21). Com isso, foi possível mapear os aglomerados urbanos com forte integração intermunicipal no Maranhão (Mapa 5). 
Figura 4 - Arranjos populacionais no Maranhão

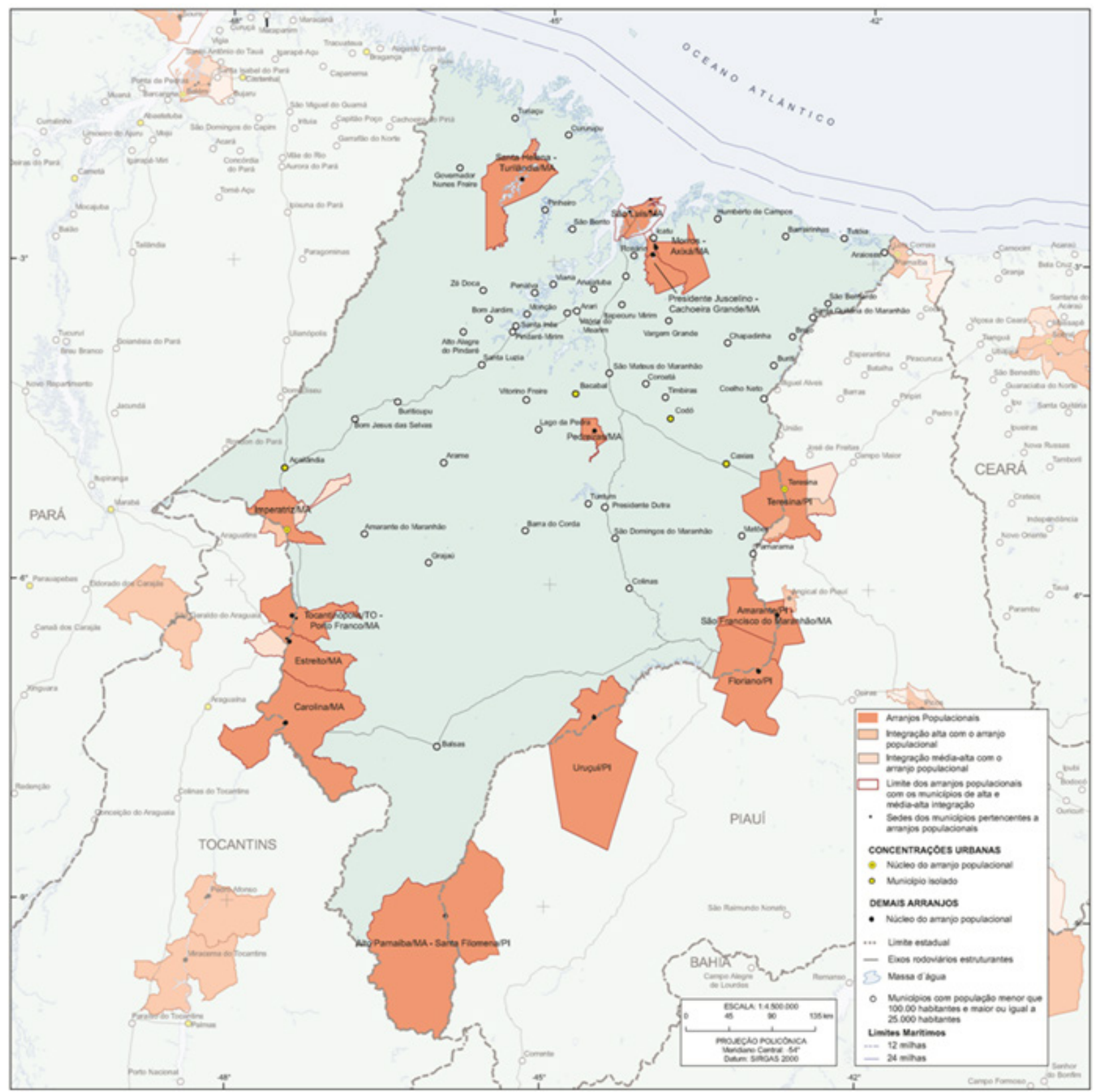

fonte: IBGE (2015, p. 128).

Conforme se depreende do Mapa 4, em todas as RM maranhenses e na RIDEGT, há municípios que formam AP, logo, apresentaram forte integração intermunicipal, seja pelas intensidades absoluta e relativa dos fluxos pendulares considerados, seja pela contiguidade das manchas urbanizadas. Assim, nos AP onde o município núcleo também é classificado como capital regional, ou seja, nos arranjos de São Luís, de Imperatriz e no de Teresina, as condições espaciais dos respectivos aglomerados urbanos atendem ao critério de "continuidade territorial" da "metrópole", nos termos da Lei Federal n. 13.089/2015. Mas, assim como nos demais casos, as áreas das regiões administrativas em tela ultrapassam os limites dos AP que englobam, ou seja, vão além dos municípios integrados à conurbação desses recortes espaciais. É o que ilustra o Mapa 5. 


\section{Mapa 5 - Limites das regiões metropolitanas com arranjos populacionais no Maranhão}

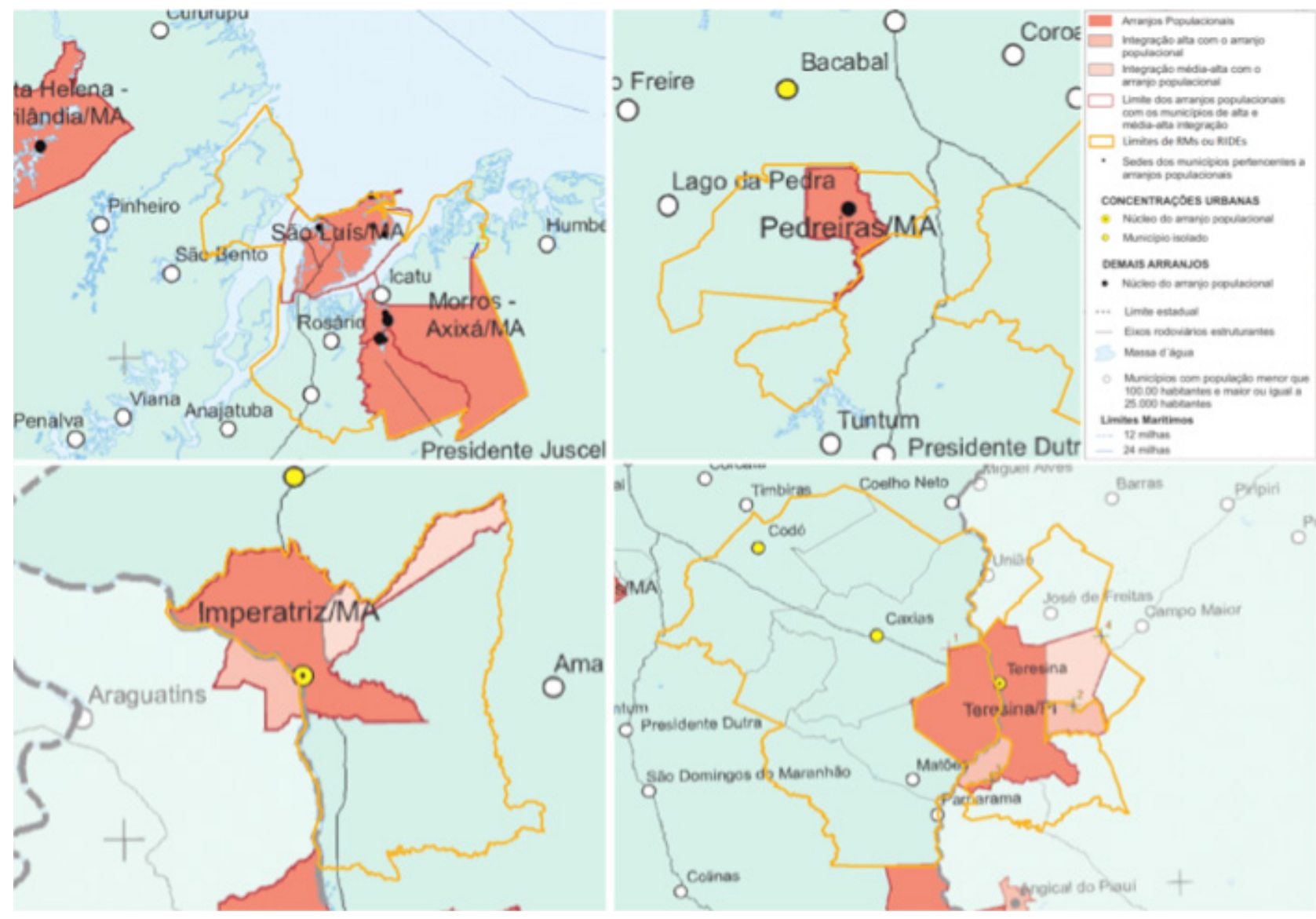

fonte: Adaptado de IBGE (2015, p. 128).

Na RM do sudoeste maranhense, apenas Davinópolis apresentou algum grau de integração suficientemente forte com Imperatriz para juntos formarem um AP, ainda que sem a presença de mancha urbana contínua entre si. João Lisboa, outro município da RM, mostrou certa relevância com a AP de Imperatriz, mas, sem haver reunido as condições necessárias para ser incorporado ao arranjo, foi indicado com integração "média-alta". Numa situação semelhante ficou São Miguel do Tocantins-TO, diferindo apenas por apresentar uma integração "alta" com o arranjo (Figuras 5 e 6).

Na Grande São Luís, foram identificados três AP: um composto pelos quatro municípios da Ilha do Maranhão e classificado como GCU, dado seu porte populacional (1.309.330 habitantes); outro formado por Axixá e Morros, com 29.190 habitantes; e o terceiro, com 29.190 habitantes, é o de Presidente Juscelino e Cachoeira Grande. Nesses dois arranjos, a intensidade dos deslocamentos pendulares se mostrou "muita baixa", e só Axixá-Morros apresentou mancha urbana contígua. Situação espacial bem diferente é a da GCU de São Luís, cujos municípios mantêm entre si uma integração de intensidade "muita alta" e mancha urbana contígua por todo o AP (Mapas 5 e 6). 
Integrante da RMLEM e da RIDEGT, o município de Timon só apresentou integração com a capital piauiense, formando com ela um AP de GCU, que também compreende os municípios de Lagoa do Piauí e Demerval Lobão, ambos do Piauí; o arranjo tinha 986.831 habitantes em 2010 (IBGE, 2015, p. 96). Dos municípios da RIDEGT, Timon foi o único a manter contiguidade da mancha urbana com Teresina, enquanto Nazária e Pau D’Arco do Piauí apresentaram integração "alta" com o arranjo, seguidos por Altos, que ficou no grau de "média-alta" integração. Então, dos 12 municípios que compõem o território, apenas sete apresentaram integração relevante com a dinâmica da região (Mapas 4 e 5).

Por fim, dos sete municípios que compõem o território da RMGP, apenas dois formam o único AP da região, cujo total populacional era de 58.401 habitantes em 2010. Pedreiras constituiu o núcleo do arranjo e apresentou mancha urbana contígua com Trizidela do Vale, município criado em 1994 por desmembramento do primeiro.

\section{Considerações finais}

$\bigcirc$ crescimento do número de RM criadas no Brasil não é em si um problema. $\bigcirc$ ponto crítico e indicativo da banalização desse instituto é o fato de a maioria dessas regiões não se constituir como espaço metropolitano. São, pois, ficções jurídicas e, como tais, se arrogam o direito de concorrer às mesmas políticas federais moldadas e destinadas a esse tipo de espaço. Com o EM, o quadro legal mudou, e agora a União passa a ter uma referência própria a ser observada para balizar essas políticas. Isso, no entanto, não significa o fim das "metrópoles de papel", nem das condições legais que as viabilizam.

Em primeiro lugar, a vigência do EM não revoga as leis estaduais instituidoras das "metrópoles de papel". Por mais que a lei federal, ao contrário da CF, traga definições de RM e AU, não há determinação constitucional que obrigue os estados a adotá-las. Nessa matéria, os únicos requisitos claramente definidos no Art. 25, §3०, da CF são o do instrumento (Lei Complementar), o da composição territorial (agrupamento de municípios limítrofes) e o do objetivo (integrar a organização, planejamento e execução de funções públicas de interesse comum). Fora isso, aí não há nenhuma definição que diferencie os três tipos de região mencionados nem exigência de lei complementar nesse sentido.

Nesses termos, a instituição das unidades administrativas referidas pode ser pautada nas peculiaridades dos contextos estaduais - ao contrário do tratamento simétrico dado às RM anteriores a 1988. Se, por um lado, isso permite aos estados instituírem RM levando em conta as próprias peculiaridades espaciais, por outro, dá margem à adoção de critérios indiferentes às condições fáticas objeto da matéria. Ao que tudo indica, foi o que aconteceu na maior parte das RM criadas depois da CF de 1988.

Realmente, o EM reflete um esforço para evitar certas arbitrariedades viabilizadas pela ausência na CF de definições que identifiquem e diferenciem RM, AU e microrregião. Porém, rigorosamente, o dispositivo apropriado para suprir essa lacuna seria a emenda constitucional - ou a lei complementar federal, se assim fosse determinado.

Com efeito, ainda é plausível interpretar que a instituição de novas RM deva - e não apenas possa - obedecer às definições do EM, mas não sem pôr em questão a plena competência dos estados na matéria. Sendo ou não os estados obrigados a instituir suas RM e AU 
conforme as definições desse diploma legal, se assim o fizerem, estarão atendendo a uma parte dos requisitos necessários para receber apoio da União em matéria de governança interfederativa, conforme o Art. 13 da lei. ${ }^{8}$

Não é segredo que uma das razões do recente aumento de RM criadas no país se deve à presunção de que a União lhes aportaria recursos específicos. Mas, agora, se os estados objetivam valer-se dessa estratégia, devem conformar as respectivas RM aos preceitos do EM. Do contrário, correm o risco de ficar à margem de qualquer política metropolitana federal que se baseie nessa lei.

Reside aí uma das questões políticas (quiçá a mais importante) relativa aos possíveis efeitos depurativos do EM na banalização das RM. Apesar de "alargar" o conceito de metrópole e não abranger todas as configurações espaciais da metropolização, a definição de RM trazida pela lei imprime mais coerência entre as condições empírica e jurídica das regiões assim instituídas. Ora, ao aplicar essa definição, encontramos espaços com as condições mínimas (ainda que não suficientes) referentes à realidade metropolitana, a saber: relevante raio de influência na rede urbana nacional e evidência da conurbação intermunicipal.

Porém, embora contenha uma "metrópole", dada RM pode expressar outra forma pela qual se banaliza esse instituto, qual seja, pela extrapolação dos limites territoriais. Mais precisamente, o limite em questão é do conjunto de municípios abarcados pelo "espaço urbano com continuidade territorial" da "metrópole", nos termos do EM.

$\bigcirc$ caso maranhense mostra como tal extrapolação pôde acontecer antes do EM (nas regiões com cidades que se enquadram no que a lei federal define como "metrópole"), intensificar-se na iminência deste (com as ampliações da Grande São Luís) e, finalmente, continuar depois de promulgada a norma (inclusive quando da instituição da RMLEM). De todo modo, convém repetir, duas das RM do Maranhão atendam aos critérios mínimos para ser reconhecidas como tais pela União, assim como a Ride de que participa Timon.

Então, como a captação de recursos federais tem sido uma das justificativas mais recorrentes entre políticos que defenderam a instituição de RM no MA (Cordeiro, 2014) - algo similar ao caso paranaense (Firkowski, 2011) -, a diminuição das proposições legislativas para se criarem novos territórios desses deve ser uma tendência. $\bigcirc$ mesmo não se pode dizer da banalização do instrumento pela extrapolação dos limites das RM para além da conurbação intermunicipal das respectivas "metrópoles", como observado no caso da última modificação legislativa atribuída à Grande São Luís.

Por fim, a banalização da instituição de RM deve ser lida como mais que puro resultado de lacunas legais. Se assim fosse, o EM deveria tolher o advento das "metrópoles de papel", o que não aconteceu. Os estados não perderam a prerrogativa de instituir suas RM segundo critérios próprios, respeitados os requisitos exigidos pela CF; mas, para não ficar à margem das políticas federais de apoio a estruturas interfederativas, essas regiões devem condizer com as definições do EM. Por isso, o tipo de extrapolação territorial observado nas RM maranhenses pode ser uma nova tendência estratégica nas escalas estaduais e municipais, se for ignorado o critério da continuidade territorial do espaço urbano da "metrópole" que, por sua vez, configura uma $\mathrm{RM}$, nos termos do EM.

8 "Art. 13. Em suas ações inclusas na política nacional de desenvolvimento urbano, a União apoiará as iniciativas dos Estados e dos Municípios voltadas à governança interfederativa, observados as diretrizes e os objetivos do plano plurianual, as metas e as prioridades fixadas pelas leis de diretrizes orçamentárias e o limite das disponibilidades propiciadas pelas leis orçamentárias anuais" (Brasil, 2015). 


\section{Referências}

ARAÚJO FILHO, V. F. Antecedentes político-institucionais da questão metropolitana no Brasil. In: CARDOSO, E. D.; ZVEIBIL, V. Z. (Org.). Gestão metropolitana: experiências e perspectivas. Rio de Janeiro: Ibam, 1996. p. 49-70.

AZEVEDO, S.; GUIA, V. R. M. Os dilemas institucionais da gestão metropolitana no Brasil. In: RIBEIRO, L. C. Q. (Org.). Metrópoles: entre a coesão e a fragmentação, a cooperação e o conflito. São Paulo/Rio de Janeiro: Fundação Perseu Abramo/Fase, 2004. p. 97-110.

BRASIL. Presidência da República. Casa civil. Lei n. 13.089, de 12 de janeiro de 2015. Institui o Estatuto da Metrópole, altera a Lei no 10.257, de 10 de julho de 2001, e dá outras providências. Disponível em: http://www.planalto.gov.br/ccivil_03/_Ato2015-2018/2015/ Lei/L13089.htm. Acesso em: 12 mar. 2019.

BRASIL. Constituição (1988). Constituição da República Federativa do Brasil. Brasilia, DF: Senado, 1988.

CASTRO, I. E. Geografia e política: território, escala de análise e instituições. Rio de Janeiro: Bertrand Brasil, 2005.

CORDEIRO, E. C. Institucionalização metropolitana sobre espaços não metropolitanos: o caso da Região Metropolitana da Grande São Luís. Dissertação (Mestrado em Geografia) - Universidade Estadual do Maranhão, São Luís, 2014.

COSTA, M. A.; TSUKUMO, I. T. L. Para uma análise-síntese: uma proposta tipológica para os sistemas de gestão das regiões metropolitanas do Brasil. In: COSTA, M. A.; TSUKUMO, I. T. L. (Org.). 40 anos de regiões metropolitanas no Brasil. Brasília: Ipea, 2013. p. 15-44.

CUNHA, F. C. A. A metrópole de papel: a representação "Londrina Metrópole" na institucionalização da região metropolitana de Londrina. Tese (Doutorado em Geografia) - Faculdade de Ciências e Tecnologia, Universidade Estadual Paulista, Presidente Prudente, 2005.

FIRKOWSKI, O. L. C. F. Metrópoles e regiões metropolitanas no Brasil: conciliação ou divórcio?. In: FURTADO, B. A.; KRAUSE, C.; FRANÇA, K. C. B. Território metropolitano, políticas municipais: por soluções conjuntas de problemas urbanos no âmbito metropolitano. Brasilia: Ipea, 2013. p. 21-51.

FIRKOWSKI, O. L. C. F. Região Metropolitana no Brasil: assim é se lhe parece... In: SIMPÓSIO DE ESTUdOS URBANOS: DESENVOLVIMENTO REGIONAL E DINÂMICA AMBIENTAL, 1., 2011, Campo Mourão. Anais... Campo Mourão, 2011.

IBGE. INSTITUTO BRASILEIRO DE GEOGRAFIA E ESTATÍSTICA. Arranjos populacionais e concentrações urbanas do Brasil. Rio de Janeiro, 2015.

IBGE. INSTITUTO BRASILEIRO DE GEOGRAFIA E ESTATÍSTICA. Regiões de influência das cidades 2007. Rio de Janeiro, 2008. 
IBGE. INSTITUTO BRASILEIRO DE GEOGRAFIA E ESTATÍSTICA. Divisão do Brasil em regiões funcionais urbanas. Rio de Janeiro, 1972.

IBGE. INSTITUTO BRASILEIRO DE GEOGRAFIA E ESTATÍSTICA. Subsídios à regionalização. Rio de Janeiro, 1968.

LENCIONI, S. O processo de metropolização do espaço: uma nova maneira de falar da relação entre metropolização e regionalização. In: SCHIFFER, S. (Org.). Globalização e estrutura urbana. São Paulo: Hucitec/Fapesp, 2004. p. 153-165.

MARANHÃO. Secretaria de Transparência e Controle. Lei Complementar n. 174, de 25 de maio de 2015. Dispõe sobre a instituição e gestão da Região Metropolitana da Grande São Luís e revoga as Leis Complementares Estaduais n. 038, de 12 de janeiro de 1998, n. 069, de 23 de dezembro de 2003, n. 153, de 10 de abril de 2013, n. 161, de 03 de dezembro de 2013, e as demais disposições em contrário. Disponível em: http://www.stc. ma.gov.br/legisla-documento/?id=4356. Acesso em: 13 mar. 2019.

MARANHÃO. Lei Complementar n. 161, de 3 de dezembro de 2013a. Dá nova redação ao art. 10 da Lei Complementar n. 38, de 12 de janeiro de1998, que dispõe sobre a Região Metropolitana da Grande São Luís e dá outras providências (para incluir o Município de Icatu). Diário Oficial, São Luís, n. 242, 12 dez. 2013, p. 1. Disponível em: http:// www.secid.ma.gov.br/files/2015/04/LCE-161_2013.pdf. Acesso em: 13 mar. 2019.

MARANHÃO. Lei Complementar n. 153, de 10 de abril de 2013b. Altera a Lei Complementar n. 069, de 23 de dezembro de 2003, que dispõe sobre a Região Metropolitana da Grande São Luís e dá outras providências. Diário Oficial, São Luís, n. 70, 11 abr. 2013, p. 1. Disponível em: http://www.secid.ma.gov.br/files/2015/04/LCE-153_2013. pdf. Acesso em: 13 mar. 2019.

MARANHÃO. Secretaria de Estado das Cidades e Desenvolvimento Urbano. Lei Complementar n. 069, de 23 de dezembro de 2003. Dá nova redação à Lei Complementar n. 038, de 12 de janeiro de 1998, que dispõe sobre a Região Metropolitana da Grande São Luís, e dá outras providências. Disponível em: http://www.secid.ma.gov.br/files/2015/04/LEI-COMPLEMENTAR-69_GRANDE-SAO-LUIS.pdf. Acesso em: 13 mar. 2019.

MARANHÃOO. Assembleia Constituinte do Estado do Maranhão. Constituição do Estado do Maranhão (1989a) (Atualizada até a Emenda Constitucional n. 069, de 12/02/2014). Disponível em: http://www.stc.ma.gov.br/files/2013/03/ CONSTITUI\%C3\%87\%C3\%83O-DO-ESTADO-DO-MARANH\%C3\%83O_ atualizada_at\%C3\%A9_emenda69.pdf. Acesso em: 13 mar. 2019.

MARANHÃO. Assembleia Constituinte do Estado do Maranhão. Constituição do Estado do Maranhão (1989b) (Atualizada até a Emenda Constitucional no 66, de 20.06.2012). Disponível em: https://www2.senado.leg.br/bdsf/bitstream/handle/ id/70443/CE_MA_EC_66.pdf?sequence=15.pdf. Acesso em: 13 mar. 2019. 
MOURA, R.; HOSHINO, T. A. P. Estatuto da Metrópole: enfim, aprovado! Mas o que oferece à metropolização brasileira? Observatório das Metrópoles, Rio de Janeiro, p. 1-14, 2015.

PAULA, C. B. Jurisprudência do STF sobre regiões metropolitanas: delimitação do papel de cada ente federativo. Monografia (Especialização em Direito Público) - Sociedade Brasileira de Direito Público, São Paulo, 2013. Disponível em: www.sbdp.org.br/ arquivos/monografia/232_Camila\%20de\%20Paula.pdf. Acesso em: 13 mar. 2017.

SERRANO, P. E. A. P. Região metropolitana e seu regime constitucional. São Paulo: Verbatim, 2009.

SOUZA, C. Regiões metropolitanas: trajetória e influência das escolhas institucionais. In: RIBEIRO, L. C. Q. (Org.). Metrópoles: entre a coesão e a fragmentação, a cooperação e o conflito. São Paulo/Rio de Janeiro: Fundação Perseu Abramo/Fase, 2004. p. 61-96.

SOUZA, C. Regiões metropolitanas: condicionantes do regime político. Lua Nova [on-line], n. 59, p. 137-158, 2003. Disponível em: http://www.scielo.br/pdf/ln/n59/a07n59.pdf. Acesso em: 27 ago. 2013. 